size, unctuons, concrete, adinose matter appeared; possibly the fluid may have become insisissated by absorption or exudation, or hydatids of a later growth, containing the more solid product, may have been generated. The presence of these cysts in the uterus occasioned much local pain, most distressing vomiting, sometimes continuing for four or five days with scarcely any intermission; paroxysms of hysteria in its most aggravated form, the patient remaining for some hours in a state of unconsciousness, or at times so convulsed as to require coercion to prevent her inflicting injuries on herself and others. Her screams at such times were so loud that the neighbours became oftentimes alarmed. Ther a can be little doubt that the rupture of the cysts on the 13 th of September expedited her recovery, for from that date the pain, vomiting, and hysteria became less nrgent, and she had no further relapse. With the exception of the loss of blood that occurred on the rupture and expulsion of the hydatids, I had no grounds for believing that the continued hainorhage was depenrent on the growth or separation of these bodies. The loss of vision was a peculiar complication, and rendered her coufinement truly irksome; for the space of nearly two years she had neither the satisfaction of seeing her friends nor any extemal olject. The above case is not without interest, and offers many points for consideration and profitable discussion.

Notting-hill, 1850 .

\section{ON A JAPANESE REMEDY FOR STERILITY.} Br E. WILLIAMS, M.D.

AFTer twenty years' absence from my native land, during which time $I$ have resided in the various islands of the Pacific Ocean and the Eastern Alchipelago, anxious for information bearing upon my profession, as $I$ have always been, $I$ could scarcely avoid picking up at various times many matters of practical importance, as well as some curious information of the mode of treating diseases, more particularly amongst the Japanese and Chinese. The results of my inquiries I will, with permission, forward (as $I$ have leisure) to THE LANcer, which has from tine to time linked me to home while sojourning in these distant lands.

Amongst the many botanical remedies that popular experience has made common in Japan and China is one that is believed to exert specific influence upon the uterus, more particularly in cuses of sterility and checked menstruation; and from the numerous cases in which I have administered it with alvantage, I am inclined to think it will become a valuable addition to onr materia medica.

The tree from which the preparation is made that possesses the virtues ascribed to it is, no doubt, one of the order Ternstromacere of $J$ ussieu, growing to the size of the English laurel, with leaves somewhat larger than the congou tea, and botanically it may be described as leaves lanceolate, alternate, serrated, downy on the under side, and emitting when bruised a strong odour resembling pulegium and sabina. Its properties are said to vary considerably with the age of the tree, likewise as to its being gathered at the full or wane of the moon, and as to the season of the year. It is perennial, and grows best in moist and sheltered places.

The mode of preparation is to take a quantity of the leaves, macerate them in as much rice-spirit (samshn) as will just moisten them for six hours; then express and give about a teaspoonful every hour, and two or tiree doses will invariably bring on the menstrual secretion, which can be maintained by a dose or two daily for any length of time.

Females in the healthy state are expected to menstruate in their eighth year in Japan and China, and should they not do so they are incligible for betrothal; therefore recourse is had to the ley tu sing with certain results.

To ensure its success, according to popular belief, the leaves must be gathered by a virgin the while nsing certain cabalistic formula, at the full of the moon, and during the burning of a certain number of highly perfumed jop-sticks.

When required for the purpose of obviating sterility, the tree must be in its second year, and also gathered with certain prescribed formulre at the wane of the moon, and equal parts of the root nust be added to the prewation, which is made in the same mamer as the preceding recuipt.

That the root is alluridiac in its effects $I$ have not the slightest doubt, as I have administered ic to auimals with obviuus results, and without any ill effects even to mules and castrati.

Having brought home some of the plant, and various draw. ings, which $I$ intend sending to the hedico-Butanical and other learned Societies, as well as sufficient to ensure a rea- sonable trial of its effects in this country, I shall feel happy to forward some of the preparation to any established member of the protession, on the promise of his giving me the result of the trial, and presentivg it according to the instructions I will forward with it.

Upper Clifton-street, Finsbury, 1850.

\section{fforeign 预enartment.}

Action of Senega, Oxysulphuret of Amimony, Hydrochlorate of Ammonia, Colchicum, Belladonna, Antin. Potass. Tartras., Flures Sulpliuris, Acetas Potassii. By Dr. Boecker.

IN the second volnme of his "Beitraege zur Heilkunde, Crefeld, 1849," the first of which has been noticed in THE LAXCars for 1850 , vol. i., No. 4, the author enters into a minute examination of the action of tire above-mentioned medicaments, with reference to the changes producel by them in the constituents of the urine, the exhalations of the lungs, and the blood. The indefatigable perseverance of the author has furnished us with a great many analyses, which clearly show the effect of these agents, and it becomes evident from this work, how little we really know at present of the intimate nature of such effects; also, that we aro far from any certainty as to therapeutical principles, and that this method of analysis is the only one which can lead to the improvement of our knowledge of the real effect of medicaments, and to the setting aside those doubts as to the proper treatment of diseases, too well known as the torment of every conscientious and scientific practitioner. We are much indebted to Dr. Boecker for the rcal improvement of therapeutical principles, which we owe to him, though we may not be always able to coincide with his theoretical views. Those who desire to become better acquainted with these theorctical opinions must refer to the volume itself; the actual results of examinam tion-that is to say, the facts adduced by Dr. Boecker are maiuly as follow:-

\section{Radix Senegae.}

a. Examination of the Urine.-The author, on two different occasions, submitted himself, and once a female patient, to a course of radix senegæ; he used from six to seven ounces of the decoction, daily, made with from half an ounce to one ounce and a haif of the root. It was found then, by nineteen analyses of the urine, passed during the use of the decoction, and by the comparison of those with the results of seven analyses of urine, passed when no medicine was taken, that the radix senegæ has only a very slight influence on the constituent parts of the urine; it became evident that the clecoction did not lessen the quantity of any of these constituents, but, on the contrary, the quintities of urea, uric acid, the phosphates, volatile salts, and extractive matters, were slightly increased, especially that of uric acid.

b. The examination of the pulmonary exhalations were conducted very carefully, and in comparing the results with those obtained before and after the use of senega, it appeared that the decoction increased the volume and the density of the exhaled air; the exhalation of carbonic acid being remarkably augmented during the use of the decoction. At the same time the frequency of the pulse diminished somewhat, and Dr Boecker adds, as a general result of 800 exeminations of the proportion between the quantity of exlaled carbonic acid and the frequency of the pulse, that the latter decreases as the former increases. The aqueous exhalations of the lungs were not remarkably altered.

c. Examination of the Blood-Dr. Boecker, in all his observations, examined the blood by the microscope, as well as by chemical analysis, and by the latter he confirmed the quantity of solid matters and water of the defibrinated blood, of the solid matters and water of the serum, of the albumen of the serum, of the salts and extractive natters of the whole anount of the sermm, of the fat of the fivine, and of the bloot-globnles. He alduces the results of fonrten examinations of blood, taken from seven indivicuals, who had been subjected to the action of the decoction of seneza, the chief of which are the following. Fine fibrine ofien increases in quantity, but often also decreases; the solid materials of the blcod are sonewhat diminished; the relutive proportion betwe alkumen and in. orgaric constituents, and extractive matters likewise dimiwishes; the crassamentum, and the serum itself, increase in proportion. During the use of senega, the llood taken from ti:e vein becomes more reddened lyy contact with the air than b-fore or after its emplorment. Hence, Dr. Boecker adds, as the general result of his examinations, the decoction of senega 